1 Anonymous. Reperfusion iniury after thrombolytic therapy for acute myocardial infarction [Editorial]. Luncet 1989;ii:655-7.

2 Wilcox RG, Olsson CG. Skeene AM, van der Lippe (i, Jenson (i, Hampton JR. Trial of tissue plasminogen activator for mortality reduction in acute myocardial infarction. Anglo-Scandinavian sudy of early thrombolysis ASSET L Lncet 1988;ii:525-30.

3 Stafford PJ, Strachan CJI, Vincent R, Chamberlain DA. Multiple microemboli after disintegration of clot during thrombolysis for acute myocardial infarction. Br.Med 7 1989;299:1310-2.

4 Gruppo Italiano per lo Streptochinasi nell'Infarto Miocardico GISSI). Effectiveness of intravenous thrombolstic treatment in acute myocardial infarction. Lancet 1986;i:397-402.

5 ISIS-2 Second International Study of Infarct Survival Collaborative Group. Randomised trial of intravenous streptokinase, oral aspirin, both or neither among 17187 cases of acute mvocardial infarction (ISIS-2). Lancet 1988;ii:349-60.
6 Payne ST, Hosker HSR, Allen MB, Bradbury H, Page RL. Transient impairment of renalfunction after streptokinase therapy. Lanct 1989;ii: 1398

7 Anisoylated Plasminogen Streptokinase Activator Complex Intervention Mortality Trial Study Group. Effect of intravenous APSAC on mortality after acute myocardial infarction: preliminary report of a placebo-controlled clinical tral. Lancet 1988:1:545-9.

8 White HD, Norris RM, Brown MA, et al. Effect of intravenous streptokinase on left ventricula function and early survival after acute myocardial infarction. $N \mathrm{Engl} / \mathrm{F}$.Med 1987;317:850-5. Jalihal S, Morris GK. Antistreptokinase titres after intravenous streptokinase. Lancet 1990;355: $184-5$

0 British Heart Foundation Working Group. Role of the general practitioner in managing patients with mvocardial infarction: impact of thrombolvtic treatment. Br Med f 1989;299:555-7. Burrell CJ Skehan VD, Cowley $\mathrm{ML}$, Barrett $\mathrm{CH}$, Mills PG. Districts' use of thrombolytic agents. Br Med f 1990;300:237-8

\title{
Multiple endocrine neoplasia type 2
}

\author{
The search for the gene continues
}

Multiple endocrine neoplasia type 2 (MEN 2) is one of the dominantly inherited cancer syndromes. In the most usual form, MEN 2A, tumours of the thyroid C cells (medullary thyroid carcinoma) are found with tumours of the adrenal medulla (phaeochromocytoma) and, in some people, parathyroid hyperplasia or adenoma.'

The gene for MEN 2A was mapped to chromosome 10 by genetic linkage in $1987 . .^{23}$ Progress since that time was reviewed at the third international workshop on MEN 2 in Heidelberg in 1989. Study worldwide of some 50 families with MEN 2A has found none in which the results are inconsistent with predisposition at the locus on chromosome 10. Even so, the possibility of heterogeneity cannot be excluded. Apart from MEN 2A two variants of MEN 2 are recognised that breed true in families: MEN 2B, in which additional phenotypic abnormalities are associated with an earlier onset of tumours and generally more aggressive behaviour of medullary thyroid carcinoma; and rare "MTC only" families in which medullary thyroid carcinoma is the only tumour, the onset is late, and the tumours are rarely if ever fatal. ' Recent data, updated at Heidelberg, suggest strongly that families with MEN 2B and perhaps those with medullary thyroid carcinoma only also have mutations at the same locus on chromosome $10 .^{+5}$ If so, once the gene(s) is cloned and sequenced comparison of the mutations that give rise to these different disease phenotypes is likely to be of considerable interest.

Before this stage can be reached the MEN 2 locus must be mapped more precisely. The MEN 2A gene has been localised to a small region defined by two sets of genetic markers, one set just above the centromere (the fibronectin $\beta$ chain ${ }^{6}$ and an anonymous DNA segment recognised by the probe TB14.34) and one set below the centromere (the interstitial retinol binding protein and the DNA segment recognised by the probe $\mathrm{MCK} 2^{7}$ ). Further progress with genetic mapping is, however, proving difficult. It depends on recombination between markers, and the region of the centromere, where the MEN 2 locus lies, is characterised by lack of recombination. This problem has directed attention to the parallel strategy of building a physical map defined by overlapping stretches of DNA identified by pulsed field gel electrophoresis. Such maps are oriented by reference to fixed points provided by a series of cell lines that can be prepared carrying different chromosome breaks that lie in the region of interest.

Even an excellent physical map, however, begs the question of how the MEN 2 gene will be recognised. One hope is that the mutation that causes MEN 2 will prove to be one that causes loss of activity of the gene (like the mutations in familial retinoblastoma and in familial polyposis of the colon).

\section{Nomenclature of MEN 2 syndromes}

At the Heidelberg meeting the organising committee made the following suggestions to achieve uniformity:

Clinical syndromes: MEN 2, MEN 2A, MEN 2B (not, for example, MEN-II, MEA, MEN-2, MEN 2a, MEN 2b, MEN 3)

Genes: MEN 2A, MEN 2B; MEN 2 for the gene for the syndrome where MEN 2A and MEN 2B are both included

Medullary thyroid carcinoma: MTC; not MCT. The two types of MTC are hereditary and non-hereditary

In that case in at least some families the MEN 2 mutation should be associated with the deletion of a sizable piece of DNA, which might easily be detected using the physical map, and the gene should almost certainly be found within the next year or so. An alternative is that the mutation that causes MEN 2 might be a single codon change leading to alteration of a single amino acid and a critical change in the conformation of the protein product. To detect a gene with that kind of mutation might require a functional assay in an appropriate cell type. The cell biology of MEN 2 is not well developed, so in this case the search might be much longer. Faced with these alternatives most laboratories are backing the search for a deletion.

Do advances of this kind in molecular genetics offer any help to clinicians? Until the gene is found molecular diagnosis cannot sort out the problem of whether an apparently isolated patient with medullary thyroid carcinoma has a hereditary disorder. In known families where two or more affected members can be studied, however, a genetic prediction based on the inheritance of DNA markers is already possible in about four fifths of cases. If only one marker is used, depending on the marker and the family members available, the accuracy of prediction is about $95-99 \%$ for children of an affected man and $90-96 \%$ for children of an affected woman..$^{910}$ (Prediction is less accurate if inheritance is from a woman because the frequency of genetic recombination between close markers and the MEN 2 gene is higher in women.) If two markers either side of the MEN 2 gene (for example, interstitial retinol binding protein and $14 \cdot 34$ ) are used together and no recombination is seen the probability of error falls to $1 \%$ or less. These figures - and the proportion of families that can be helped-will improve as more markers are defined.

As with all such genetic tests much is still to be learnt about 
how doctors and families will use the information and how best to present it. The first indications are that in multiple endocrine neoplasia type 2 there will be little demand for antenatal diagnosis because of the low morbidity of the condition and the availability of biochemical screening leading to effective surgical treatment. Children predicted to carry the gene will probably be selected for earlier and more careful biochemical screening. What is not clear is how accurate the test must be before the clinician and the family are happy for biochemical screening to be discontinued if the prediction is negative.

Director,

Cancer Research Campaign Human Cancer Genetics Research Group, University of Cambridge, Cambridge CB2 1QP
1 Thakker RV. Ponder BAJ Multiple endocrine neoplasia, Baillieres Clin Endocrinol Metab 1988:2:1031-67.

Mathew CGP, Chin KS, Easton DF, et al. A linked genetic marker for multiple endocrine neoplasia type 2 a on chromosome 10. Nature 1987;328:527-8.

Simpson NE, Kidd KK, Goodfellow PN, et al. Assignment of multiple endocrine neoplasia type $2 \mathrm{~A}$ to chromosome 10 by linkage. Nature 1987;328:528-30.

4 Jackson CE, Norum RA, O'Neal LW, Nickolai TF, Delaney JP'. Linkage between MEN 2B and chromosome 10 markers linked to MEN 2A. Am f Hum Genet 1988:43:A147.

Noll WW, Bowden DW, Maurer LH, et al. Genetic mapping of familial medullary carcinoma of the thyroid/multiple endocrine neoplasia type $2 \mathrm{~A}$ with polymorphic loci on chromosome $10 . \mathrm{Am} f$ Hum (ienet 1988;43:A29.

$6 \mathrm{WH}$ J. Goodfellow PN, Giuffra I.A, at al. Fibronectin receptor beta subunit locus: DNA polymorphisms and linkage mapping studies based on non-CEPH families. Cytogenet Cell Genet $1989 \cdot 51: 1110-1$.

7 Nakamura Y, Mathew CGP, Sobol $\mathrm{H}$, et al. Linked markers flánking the gene for multiple endocrine neoplasia type $2 \mathrm{~A}$. (ienomics 1989:5:199-203.

8 Benham F, Hart K, Crolla J, Bobrow M, Francavilla M, Goodfellow PN. A method for generating hybrids containing non-selected fragments of human chromosomes. Genomics 1989;4:509-17. elenius H, Mathew CGP, Nakamura Y, et al. Application of linked DNA markers to screening families with multiple endocrine neoplasia type 2 A. Eur I Surg Oncol (in press).

0 Sobol H, Nared SA, Nakamura $Y$, et al. Screening for multiple endocrine neoplasia type $2 \mathrm{~A}$ with DNA-polymorphism analysis. N Engl f Med 1989;321:996-1001.

\section{Bulimia nervosa}

\section{Antidepressant or cognitive therapy is effective}

The eating disorder bulimia nervosa was first described 10 years ago. ${ }^{1}$ Since then more than 50 studies of its prevalence have been conducted and there have been over 20 controlled treatment trials. With a decade of research behind us, it seems timely to consider what has been learnt.

Initially the criteria used to diagnose the disorder were very different in North America and in Britain. ${ }^{2}$ These differences largely disappeared in 1987 with the introduction in the United States of the DSM-III-R definition, ${ }^{3}$ which was broadly similar to the more restrictive criteria already in use in Britain. The initial differences undoubtedly contributed, however, to the divergent views that were held over the character, prevalence, and treatment of the disorder.

It is now agreed that bulimia nervosa has three key features. ${ }^{12}$ Firstly, there is loss of control over eating with recurrent episodes of bulimia. Typically these episodes of overeating occur in secret and are a source of shame and self disgust. Secondly, there are extreme attempts to control shape and weight; these include self induced vomiting, strict dieting, and the misuse of purgatives and diuretics. Thirdly, there are disturbed attitudes to shape and weight, which resemble those found in anorexia nervosa. These attitudes are central to the psychopathlogy of the disorder ${ }^{2}$ and have been described as "a morbid fear of becoming fat"' or a "persistent overconcern with shape and weight." "Commonly associated clinical features include a high level of general psychiatric symptoms, particularly those associated with depressive disorders, and impaired social functioning.

The physical features of bulimia nervosa have been less extensively studied than those of anorexia nervosa. The most common physical symptoms are fatigue, feeling "bloated," "puffy cheeks," irregular or absent menstruation, and toothache. $^{+5}$ Few abnormalities tend to be found on examination, and body weight is usually within the normal range. Occasionally the salivary glands, particularly the parotid glands, are enlarged, and this accounts for some complaints of facial swelling. ${ }^{67}$ The pathophysiology of this hypertrophy is unclear. In those patients who have vomited frequently for some years there may be erosion of the dental enamel, especially of the ligual surfaces of the teeth. ${ }^{8}$ This accounts for most complaints of toothache. In addition, some patients who have repeatedly induced vomiting by using their fingers to stimulate the gag reflex have a characteristic distribution of calluses on the dorsum of the hand.
Various abnormalities may be found on laboratory testing. About half the patients have electrolyte disturbance, the most common abnormalities being hypochloraemia, hypokalaemia, hyponatraemia, and a raised bicarbonate concentration. ${ }^{9}$ Very occasionally these abnormalities are life threatening. They result from the self induced vomiting and the misuse of purgatives and diuretics. The nature of the disturbance depends on the predominant behaviour: vomiting is associated with metabolic alkalosis, whereas metabolic acidosis is characteristic of purgative misuse. Another abnormality sometimes found on laboratory testing is a raised serum amylase activity, ${ }^{10}$ usually with high activities of both isoenzymes. The explanation for this increase is unclear. With the exception of severe electrolyte disturbance, none of these physical abnormalities merits direct intervention: most resolve rapidly in response to treatment directed at the eating disorder itself.

The diagnostic status of bulimia nervosa has been the subject of much debate. Is it a discrete psychiatric syndrome or a variant of another psychiatric disorder? Some authors have argued that bulimia nervosa is closely related to major depressive disorder." This view is difficult to sustain in the light of the mounting evidence of differences between the disorders in phenomenology, distribution, familial transmission, biological correlates, and course. ${ }^{12}$ Others have emphasised the association with substance abuse and "borderline personality disorder," ${ }_{1+}$ but these associations are found in only a few patients. ${ }^{15} 16$ The disorder with which there is undoubtedly a close relation is anorexia nervosa. ${ }^{2}$ Bulimia nervosa and anorexia nervosa have very similar clinical features, and between a third and a half of patients with bulimia nervosa have met strict diagnostic criteria for anorexia nervosa in the past, while many others have almost, but not quite, met these criteria. ${ }^{17} \mathrm{~A}$ case may be made for viewing anorexia nervosa and bulimia nervosa as different expressions of a single psychiatric disorder ${ }^{2}$; but until data are available that allow the prognostic and therapeutic implications of the two diagnoses to be compared (thereby testing their predictive validity) it seems premature either to amalgamate the two diagnostic concepts or to give one diagnosis precedence over the other. This is the position taken in DSM-III-R, ${ }^{3}$ and as a result some patients are eligible for both diagnoses - namely, those who are both seriously underweight and have episodes of bulimia. 